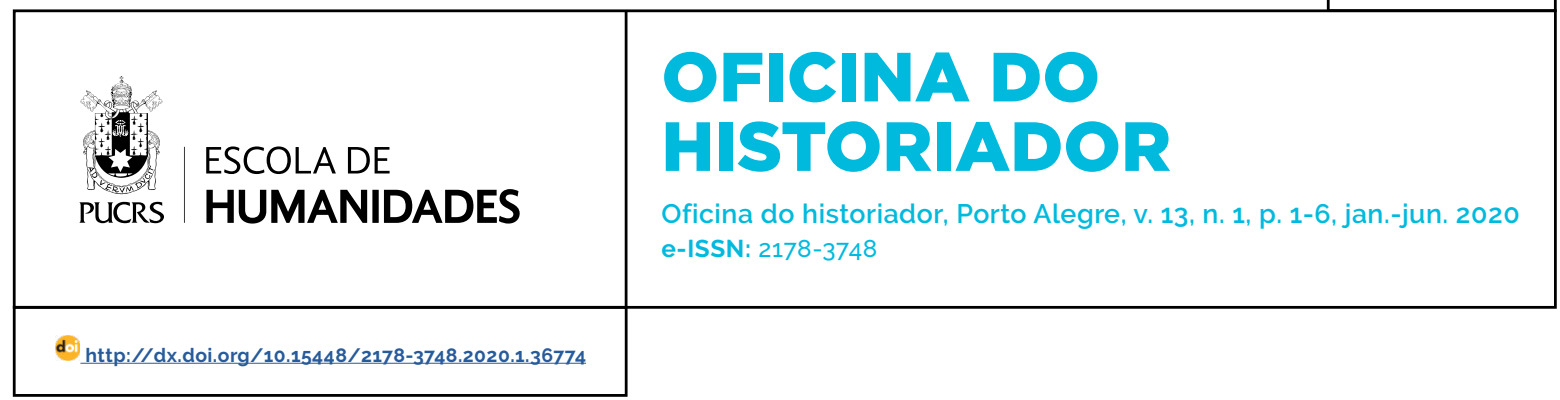

ENTREVISTA

\title{
Entrevista com o Professor Dr. José Alberione dos Reis: relações entre Arqueologia, ontologias e História
}

\section{Carlos Eduardo Ferreira \\ Melchiades $^{1}$ \\ orcid.org/0000-0003-3904-6607 \\ carlosmelchiades@hotmail.com.br}

Recebido em: 7 jan. 2020. Aprovado em: 8 jan. 2020. Publicado em: 14 jun. 2020.

\section{(c) (1)}

Artigo está licenciado sob forma de uma licença Creative Commons Atribuição 4.0 Internacional.
Quando a equipe do Laboratório de Pesquisas Arqueológicas da PUCRS, a qual pertenço, aventa sobre a possibilidade de organizar um dossiê, coube a mim a escolha e realização de uma entrevista que se encaixasse nos temas propostos.

Porém, conversando com o coordenador da pesquisa, o Professor Klaus Hilbert, pensamos em conversar justamente com alguém que não gostasse de se encaixar, que preferisse viver, e principalmente, pensar fora da caixa.

Ajustado esse termo, demoramos aproximadamente cinco segundos para chegarmos ao mesmo nome, o do Professor Dr. José Alberione dos Reis. Contando com a nossa sorte de existir, entre os professores, um estreito relacionamento, começo a pensar, então, nos questionamentos que poderiam suscitar a leitura pelo público, mas principalmente a curiosidade do entrevistado.

Assim se descobre, estando na pele de um acadêmico sem experiências anteriores em entrevistas, que formular a pergunta é muito dificil para quem está somente acostumado a escrever as respostas. Percebo, tardiamente dirão muitos, que para entrevistar mentes brilhantes temos que, de alguma maneira, tentar elevar o nosso "sentir", ainda que parcialmente ou temporariamente.

Contando com o auxilio e a orientação dos amigos e do professor Hilbert, formulo, então, algumas questões, em uma tentativa de fazer jus ao entrevistado. A primeira tentativa, prontamente respondida com uma presteza educadíssima, deixa-me com fome. Apesar de alguns pontos não andarem na direção que espero (entendivel, porém frustrante), as brilhantes respostas às parcas perguntas me fazem entender por onde devo dar seguimento ao processo, o que perguntar a mais na tentativa de abrilhantar ainda mais as respostas e os desafios propostos pelo entrevistado.

Assim, segue a segunda leva de perguntas, aprofundando os argumentos e ampliando o campo de discussão. Me considero um privilegiado em ter aprendido de diversas formas, formulando as questões, alinhando as ideias para as próximas e lendo (e relendo) as respostas.

O Professor Doutor José Alberione dos Reis, segundo sua descrição na

Pontifícia Universidade Católica do Rio Grande do Sul (PUCRS), Porto Alegre, RS, Brasil. 
plataforma Lattes, "Possui graduação em história pela Universidade de Caxias do Sul (1993), mestrado em História pela Pontifícia Universidade Católica do Rio Grande do Sul (1997) e doutorado em História pela Universidade Estadual de Campinas (2004)"

Atualmente é professor do Bacharelado em Arqueologia e atua como pesquisador da Universidade Federal do Rio Grande (FURG). Ainda segundo o Lattes, "tem experiência no ensino e na pesquisa em áreas da Arqueologia, atuando principalmente nos seguintes temas: teoria em arqueologia, epistemologias da arqueologia, filosofia da ciência, cosmologias ameríndias e arqueologias." Porém, não é nas definições que encontramos a razão para a entrevista, mas nas fugas delas. A busca por uma Arqueologia não classificável, não europeia, não esquecedora e não negligenciadora é um dos motes, a sempre aberta argumentação sobre o campo epistemológico e suas abordagens, mais outra.

Saliento, ao final desta breve introdução, um pedido do Professor Alberione para que fique claro que somente as respostas aos questionamentos são de autoria dele, e que essas não foram, de maneira nenhuma, editadas. Desejo a quem for ler que tenha o mesmo sentimento de conhecimento instigado que tive ao participar deste processo. Boas leituras!

\section{Como se pode estabelecer uma relação entre} os três campos de estudo que compõem a base deste dossiê?

Tomando por base esses três campos, no que diz respeito ao campo da Arqueologia, atualmente, estão desafiadoramente transrelacionados. De um lado, pela constatação de que possiveis fronteiras entre esses três campos se foram, se diluíram, e, talvez não mais existam. Não devam mesmo mais existir. De outro lado, não entendo mais qualquer possibilidade de se fazer Arqueologia que não seja estabelecendo relações de compromissos e regimes de conversação entre qualquer campo do conhecimento humano e, principal e majoritariamente, estabelecer regimes de conversação com pessoas ditas subalternas, nativas, indigenas, camponesas, das periferias urbanas, dos estigmas de gênero e todas as demais pessoas ainda sob o jugo dos preconceitos culturais, sociais e ideológicos. A Arqueologia, isolada no formal-funcional que a aprisiona na academia, não representa mais nenhum lugar de poder sobre suas possiveis abrangências e lugares de enunciação em relação ao que seja conhecimento, dito científico. Por isso, a palavra-chave é mesmo relação, o que implica saber dialogar, ceder, reconhecer e aceitar os mais diferentes regimes de conversação e de enunciação sobre o mundo e sobre a humanidade.

\section{Na sua opinião como essas relações deveriam ser mais aprofundadas pelos arqueólogos em formação? E pelos formadores?}

Para inicio de resposta, na própria pergunta há, ainda, a armadilha de reforçar o gênero masculino como natural. Enquanto cairmos nessa armadilha que naturaliza relações de poder, reforçando o patriarcado como gênero condutor do conhecimento e da humanidade, não estaremos estabelecendo relações, conversações, e sim deformações. No alunado do bacharelado em Arqueologia, na Furg, a maioria são mulheres e demais LGTB. Não vejo mais essa dicotomia, que reforça relações de poder, entre formador $x$ professor e formador $x$ aluno. Estamos juntos, no ensino onde atuo, em constante processo de mútuo aprendizado. Aprofundar relações, no âmbito do ensino em um bacharelado em arqueologia, é, principalmente, enfrentar os ainda lugares de poder que reforçam essa dicotomia caduca - quem forma e quem é formado. Manter isso é deformar, no vazio.

\section{Como podemos tirar a Arqueologia da prisão acadêmica, no momento em que a academia sente a exclusão da sociedade, talvez, exatamente por ter se excluido primeiro?}

Em se mantendo essa metáfora de uma possivel "prisão acadêmica" ela é autocriada. É uma prisão narcísica. A Arqueologia, desde 
que institucionalizada nas paredes acadêmicas, criou essa prisão de conforto ao se isolar nesse lugar. Os impérios coloniais eurocêntricos tinham a mais absoluta necessidade de que, a partir da academia, viessem plausiveis justificativas científicas para as suas ações de domínio e de extermínio nas colônias. Esse suporte, dentre outros, veio a partir do nascimento da Antropologia e da Arqueologia na academia, como instituições científicas. Para a Arqueologia ficou o lugar de fornecer conexões entre o presente e o tal passado. Essas conexões visavam estabelecer, dentro da tal cientificidade, quem era e quem não era gente, pessoas, progresso, conhecimento etc. Sempre tendo em mira, para o âmbito da Arqueologia, o tal passado - no singular, obviamente. Já, em outras respostas desta entrevista, apresento saídas dessa prisão. A Arqueologia tem, desde muito tempo, a chave para abrir as portas dessa prisão. Só que reluta em abri-la.

A partir de uma divisão entre processualismo e pós-processualismo, seria a abordagem ontológica uma espécie de pós-pósprocessualismo? Ou seria a proposta de quebra dessas classificações?

Esta tal denominada "abordagem ontológica" vem, mais uma vez "de fora" do âmbito que concerne ao lugar de produção do conhecimento ainda chamado de Arqueologia. Estas classificações: Histórico-Culturalismo/ Processualismo/Pós-Processualismo somente ainda permanecem em um âmbito disciplinar, dentro do ensino acadêmico de Arqueologia. Não tem mais sentido discursivo e epistemológico em um sentido mais amplo dentro da Arqueologia. Nem quebra de classificações e nem a reboque do Pós-Processualismo. Trazer debates ontológicos para dentro da Arqueologia, nesses tempos atuais, é mais uma tentativa do, no meu entendimento, mais absoluto e necessário: o nome, o substantivo, a denominação ou que mais seja - Arqueologia - é que precisa ser destruído e novamente construído. Arqueologia não tem mais existência!

O Senhor poderia explicar melhor a quebra da Arqueologia? Como se daria a reconstrução dela? Ainda, como fugir do eurocentrismo dominante principalmente no campo teórico?

Desde seus inícios, a Arqueologia, enquanto campo de produção de conhecimento científico, não se dispôs e não assumiu possibilidades de compromissos de incluir outras vozes em seus discursos, que não as da ciência. A voz da Arqueologia tem sido a autoridade absoluta sobre o que dizer, explicar e interpretar sobre as materialidades da vida humana no planeta Terra. Desde que a Arqueologia se inseriu no projeto da Modernidade tem sido assim. Tal projeto, para a Arqueologia, diz o seguinte: existe um passado remoto, distante, oculto; somente o campo do conhecimento arqueológico tem acesso a esse passado; apenas os arqueólogos têm a senha para decifrar e desocultar esse passado. Portanto, a tal "prisão acadêmica", da qual falamos na pergunta anterior, está no nome, no substantivo. Tanto, que faz muitos, muitos anos que o substantivo - Arqueologia - precisou ser acompanhado de tantos e tantos adjetivo que dão suposta vida à agonia desse campo do conhecimento. É sempre Arqueologia de algo, Arqueologia do, Arqueologia mais algo, algo mais Arqueo. Nesse sentido, desta pergunta, estabeleço regimes de conversação com as ideias do Cristóbal Gnecco², do Alejandro Haber $^{3}$ e do Nick Shepherd. ${ }^{4}$

Apesar de não serem pesquisadores "jovens", nomes como Ingold, Descola, Viveiros e, principalmente, Latour estão na "crista da onda" da chamada mudança de abordagem que a Ontologia se dispõe quando trabalha com a história e a Arqueologia. Isso se dá por alguma razão em especial?

\footnotetext{
Anti decálogo - diez ensayos (casi) arqueológicos. Popayán: Universidad del Cauca/Sello Editorial, 2017 
Entendo que seja mais uma das modas eurocêntricas que chegam até nós, abaixo do Equador. Precisamos manter atenção para com a velha lição que Oswald de Andrade apresentou no Manifesto Antropofágico. Nós, latinos do Sul, temos que saber comer tudo o que vem da Europa, do Norte. Cagamos o que não serve. Utilizamos o que sabemos de serventia para nós, diante dessas modas eurocêntricas e das demais.

Seguindo no cerne dessa discussão, afora a valorização da pesquisa local, como transformar o País, ou alguma região dele, em formador de conteúdo original, uma vez que, além de modismos eurocêntricos, vemos uma defasagem na discussão de alguns anos entre o lá e o cá. Ou, existe a necessidade de importação teórica defasada?

Bueno! Arqueologia nada transformará se não iniciar qualquer rumo de transformação de dentro de si mesma. A Arqueologia, no estado geral em que hoje se encontra não transforma, mas reforça preconceitos, exotismos, lugares de fala e de poder. Quanto à importação de teoria elas já chegaram destruindo, desde a modernidade eurocêntrica, a partir do confronto que o colonizador branco trouxe nas suas cabeças e nos seus corações. Isso está muito bem expresso, por exemplo, no pensamento de V. Y. Mudimbe ${ }^{5} \mathrm{e}$ no pensamento de Rodolfo Kusch. ${ }^{6}$ Se tivermos que importar teorias que seja de nossos parceiros latino-americanos e africanos.

O que leva a discussão epistemológica em Ciências Humanas e Sociais a enfrentar resistência no contexto acadêmico atual?

O atual contexto antidemocrático, repressivo e intolerante no cenário geral brasileiro, provoca resistências. Porém, dentro da academia e, em particular, no âmbito do ensino público federal, no que concerne a discussões epistemológicas, temos, para além do que possamos denominar de resistência, muita preguiça, muita desinformação a partir de tanta informação. Pouco se lê, pouco se estuda e muito se fala, se esbraveja e se grita sem argumentos, sem paciência e sem respeito ao ouvir antes de sair vomitando apressadas e superficiais ditas "opiniões".

A partir dessa pressa em produção, e se sabendo das cobranças institucionais/ sociais para uma quantidade em detrimento à qualidade das pesquisas, como o senhor acha que deva ser modificada a relação entre - professor/pesquisador e a sua produção de conteúdo? Como fazer para acabar com o imediatismo cultural e a preguiça epistêmica?

É como eu tenho feito, do lugar onde atuo, o que posso responder. Acredito no movimento de superação dessa preguiça, transformando-a em resistência, a partir do interesse daqueles poucos alunos que me procuram para atuações e ações dentro da academia, fora do cotidiano disciplinar. Uma temática que tem surgido por aqui, no bacharelado em Arqueologia, é sobre os confrontos e ou os diálogos possiveis entre a ciência e a fé, entre a ciência e a espiritualidade. Temos desenvolvido encontros e atividades sobre essas temáticas através do Lume Observatório das Coisas Contemporâneas (LOCCO).

Sob sua ótica, sendo o senhor um professor com vasta experiência, é possivel abordar ontologias, perspectivismo e as suas relações em um curso de graduação nos moldes que existem hoje?

Sim, é possivel, sem problemas. Ao menos onde trabalho, na FURG. Já venho, a alguns anos, abordando essas temáticas em sala de aula. Inclusive, já realizamos, durante um semestre, uma disciplina exclusiva sobre tais temáticas - ontologias, perspectivismo, cosmologias amerindias - dentro do bacharelado em Arqueologia. 
O senhor concorda que a Arqueologia carece de discussões entre os que a praticam no mercado e os que a abordam na academia? Como poderia ser estreitado esse laço? Seria possivel, sob a sua ótica, uma abordagem relacionando os temas deste dossiê em uma prática arqueológica não vinculada à academia?

Não falo mais sobre esse assunto.

Como o senhor vê o papel do professor universitário em Arqueologia na abordagem conceitual e interpretativa utilizada, de maneira geral, nas práticas de licenciamento arqueológico?

Me abstenho de responder.

Como, na sua opinião, as mudanças de pensamentos teórico-epistemológicos poderiam ser melhor aproveitadas nos debates, tanto dentro como fora do espaço acadêmico?

O primeiro ponto é, ainda, nos tempos contemporâneos, constatarmos a existência de tais espaços do dentro e do fora da academia. Isto é, ainda se goza no prazer de ter a tal Academia apartada da Sociedade, nesse jogo do dentro e do fora. Uma excrescência ideológica e epistemo-ontológica!

O segundo ponto é no de dentro do ensino nos cursos de bacharelado em Arqueologia espraiados pelo Brasil. Enquanto persistir, precipuamente, nesses cursos, a hegemonia do formal-funcional sobre as coisas humanas; as abordagens deterministas ambientais e biológicas; os discursos pautados na visão eurocêntrica de que Arqueologia é estudo do passado - passado é a maldição da arqueologia! -; o menosprezo e o descaso em estudar ou, ao menos, ler tantas etnologias e etnografias que a antropologia brasileira e latino-americana vem produzindo. Não há debates, nem diálogos e nem regimes de conversação simétricos no âmbito das formações acadêmicas por entre os cursos de Arqueologia existentes neste país.
Com essa impactante visão sobre como se ensina e discute Arqueologia no Brasil, como o senhor vê a possibilidade de existir uma base curricular comum dentro dos cursos de bacharelado em Arqueologia?

Seria possivel uma discussão sobre um mínimo de assuntos/textos/autores locais a serem abordados? Ou cada curso deve contar com sua especificidade e a capacidade dos seus professores/organizadores/reitores/de otimizar a sua particularidade no intuito de criar um pesquisador apto, porém individual?

Respondo as duas questões conjuntamente. Talvez uma base curricular comum no âmbito das disciplinas técnicas e de metodologias, necessárias no ensino e na profissionalização de quem se denomina arqueólogo. Abordagens ditas locais e/ ou particulares existem e necessitam de peculiares cuidados em termos curriculares. Os contextos do bacharelado em Arqueologia, por exemplo, na UFOPA (Universidade Federal do Oeste do Pará) não são os mesmos daqui da Furg, no extremo sul. É preciso, no meu entendimento, prestar atenção em possiveis especificidades, particularidades na elaboração e na aplicação das disciplinas que compõem os curriculos dos bacharelados. Porém, a maior riqueza, o maior estímulo e o grande prazer e alegrias de vencer preguiças, de estimular as resistências, de provocar novas e outras abordagens dentro do cotidiano disciplinar do ensino no bacharelado em Arqueologia onde atuo vem da mais ampla e rica diversidade de origens socioculturais, de etnicidades, de visões de mundo do alunado. Tenho trabalhado com pessoas originadas dos mais diversos locais do Brasil e do exterior. Aqui estamos na zona de fronteira onde se fala português e espanhol como línguas comuns. Essa diversidade colorida, de tantos diferentes sotaques, é provocadora em aberturas para as mais variadas temáticas no cotidiano do ensino e fora dele. Também penso que se deve prestar mais atenção e abertura de mentes e de corações, a partir de nossos lugares de suposto saber enquanto ditos professores, para aquela curiosidade, ingênua e infantil, que o alunado traz ao procurar e ingressar neste campo do conhecimento acadêmico denominado de Arqueologia. 
Carlos Eduardo Ferreira Melchiades

Doutorando em História na Pontificia Universidade

Católica do Rio Grande do Sul (PUCRS, Porto Alegre, RS, Brasil).

\section{Endereço para correspondência}

\section{Carlos Eduardo Ferreira Melchiades}

Pontificia Universidade Católica do Rio Grande do Sul

Av. Ipiranga, 6.681, Prédio 40

Partenon, 97010-082

Porto Alegre, RS, Brasil 